\title{
A tomografia computadorizada como método de guia na ablação de massas renais: Uma revisão de literatura
}

Computerized tomography as a guide method in the ablation of renal mass: A

literature review

Juliana de São Leão Barbosa ${ }^{1 *}$; Carlos Danilo Cardoso Matos Silva ${ }^{2}$

${ }^{1 *}$ Escola Bahiana de Medicina e Saúde Pública, EBMSP; Salvador-BA, Brasil, 40290-000 jull.yana.21@hotmail.com (autor correspondente)

${ }^{2}$ Faculdade Nobre, Feira de Santana-BA, Brasil, carloscardoso.fsa@gmail.com; https://orcid.org/0000-0001-6536-724X

\section{Resumo}

É cada vez maior o número de diagnósticos do carcinoma renal ainda na sua fase inicial em virtude das novas tecnologias usadas nos exames de imagem, que na maioria das vezes detectam essas massas em tamanho pequeno nos pacientes assintomáticos. Atualmente, as terapias disponíveis mais utilizadas para o tratamento são: quimioterapia, radioterapia e a nefrectomia radical ou parcial. Nesse contexto, o crescente uso da terapia ablativa, em seus diferentes métodos como a técnica de ablação por radiofrequência e a técnica de crioablação, traz um aumento na perspectiva e qualidade de vida dos pacientes acometidos por esta doença. $\mathrm{O}$ principal objetivo deste estudo foi identificar os artigos científicos publicados em periódicos indexados em Scielo e Pubmed, no período de 2010 a 2019, que apresentam as técnicas ablativas e sua aplicabilidade para o tratamento do carcinoma renal. Do tipo descritivo exploratória, com abordagem qualitativa, esta pesquisa bibliográfica demonstra e caracteriza. $\mathrm{O}$ estudo relata o conhecimento sobre a doença e descreve as novas técnicas usadas na terapia ablativa dos carcinomas renais que podem ser guiadas por métodos de imagem como a tomografia computadorizada. Assim o estudo foi subdividido em tópicos que contemplam terapias ablativas, radiofrequência ou radioablação e crioterapia ou crioablação.

Palavras-chave: Técnicas Ablativas. Carcinoma Renal. Tomografia Computadorizada. Criocirurgia. Ablação.

\footnotetext{
Abstract

The number of diagnoses of renal carcinoma is still increasing in its early stages due to the new technologies used in imaging studies, which often detect these small masses in asymptomatic patients. Currently, the available therapies most commonly used for treatment are: chemotherapy, radiotherapy and radical or partial nephrectomy. In this context, the increasing
} 
use of ablative therapy, in its different methods such as Radiofrequency Ablation Technique and Cryoablation Technique, brings an increase in the perspective and quality of life of patients affected by this disease. The main objective of this study was to identify scientific articles published in journals indexed to Scielo and Pubmed, from 2010 to 2019, which present the ablative techniques and their means of applicability for the treatment of renal carcinoma. Exploratory descriptive type, with qualitative approach, this bibliographic research demonstrates and characterizes. The study reports knowledge about the disease and describes the new techniques used in ablative therapy for renal carcinoma that can be guided by imaging methods such as computed tomography. Thus the study was subdivided into topics such as: ablative therapies, radiofrequency or radioablation and cryotherapy or cryoablation.

Keywords: Ablative Techniques. Renal Carcinoma. Computed Tomography, Cryosurgery. Ablation.

\section{Introdução}

Desde 2003 o câncer é considerado um problema de saúde pública pelo Instituto Nacional do Câncer (INCA), estando entre as dez maiores causas de mortalida de a nível mundial. Segundo a Organização Mundial de Saúde, em 2030 a doença pode chegar a 27 milhões de casos e ser responsável por 17 milhões de mortes. Ainda segundo estimativas, no Brasil podem ocorrer 600 mil novos casos de câncer por ano no biênio de 2018-2019 (INCA, 2020).

Com incidência estimada de 7 a 10 casos para cada 100 mil habitantes no Brasil, o câncer renal é o mais letal quando se fala em neoplasias urológicas, uma vez que $40 \%$ dos pacientes morrem com esta doença. Ele é responsável por cerca de 2 a 3\% dos tumores malignos, sendo o Carcinoma Renal de Células Claras (CRCC) o tipo mais frequente, chegando a 75\% dos casos, atingindo mais a faixa etária entre 50 e 70 anos de idade, principalmente o sexo masculino. $\mathrm{O}$ seu prognóstico depende de fatores como idade do paciente, rapidez do diagnóstico e do tratamento da doença. A detecção e caracterização dessas massas renais podem ser feitas através de exames de imagem como ultrassonografia, tomografia computadorizada ou ressonância magnética (INCA, 2019).

O exame de tomografia multifásico com a administração do contraste endovenoso é o exame radiológico mais utilizado no diagnóstico dos Carcinomas de Células Renais (RCC), através dele é possível obter informações sobre a função e morfologia do rim contralateral, avaliar a extensão do tumor, envolvimento venoso, aumento dos linfonodos e adrenais. O USG 
abdominal amplificado por contraste pode ser usado em casos específicos assim como a Ressonância magnética (RM), que pode ser reservada para pacientes com possível envolvimento venoso ou contra indicação para o uso do contraste iodado (LJUNGBERG et al., 2019). De acordo com LJUNGBERG et al. (2019), a indicação do tratamento do carcinoma das células renais depende de alguns fatores como localização e tamanho do tumor, função renal, comorbidade e característica patológica.

O tratamento do carcinoma renal evoluiu da nefrectomia radical do rim acometido pelo tumor para nefrectomia parcial, ou seja, retirada apenas do tumor, preservando o parênquima renal. Posteriormente veio a nefrectomia parcial laparoscópica, um método minimamente invasivo que permite o tratamento do tumor de forma menos dolorosa para o paciente, apresentando resultados semelhantes aos dos métodos anteriores, e com uma recuperação mais rápida. Entretanto, pesquisas mais recente acerca de métodos menos invasivos têm permitido desenvolver a termoablação que, além de proporcionar um tratamento menos doloroso e uma recuperação mais rápida, diminui o tempo de internamento e, consequentemente, o risco de infecções (QUEIROZ, 2011).

Este novo método utiliza fonte de frio (crioablação) e calor (radiofrequência) como principais terapias para o tratamento do carcinoma renal. Em 1995, a crioablação foi usada pela primeira vez no tratamento das pequenas massas renais, com o objetivo de provocar a destruição dos tumores através da aplicação controlada de frio provocado por gases como o argônio líquido ou o nitrogênio. E a técnica pode ser usada em cirurgia aberta laparoscópica ou percutânea. Este novo método chegou ao Brasil em 2006 e foi implantado no Hospital Sírio Libanês (HSL). Desde que iniciou a realização do procedimento, o hospital registrou 260 casos com alto sucesso terapêutico (Silva, 2013).

A termoablação é um tratamento alternativo para as massas renais, geralmente indicado para pacientes com tumores pequenos $(<4 \mathrm{~cm})$, pacientes com rim único e que apresentam função renal marginal, tumores múltiplos ou cirurgia renal prévia. Ela pode ser realizada através da radioablação, com a utilização de corrente de radiofrequência introduzida no tumor por eletrodos ou através da crioablação, que vai provocar o congelamento das células com gases nobres introduzidos no tumor através de crioprobes guiados por ultrassom ou tomografia 
computadorizada (Queiroz et al., 2011).

Ao reconhecer a importância deste método percebe-se a relevância prática, social e teórica deste estudo. Em relação ao aspecto prático, os dados obtidos poderão trazer novos conhecimentos e auxiliar os profissionais de saúde para o desenvolvimento dessa nova técnica de tratamento das massas renais, mostrando a eficácia do tratamento desse tipo de carcinomas através da ablação guiada pela tomografia computadorizada através das imagens adquiridas em tempo real. Em relação à teoria, os dados empíricos poderão estimular a realização de novas investigações, haja vista a possibilidade de lacunas no conhecimento a ser produzido.

Portanto, torna-se necessário ampliar as pesquisas na área, a fim de expandir o conhecimento sobre a ablação no tratamento do carcinoma renal e sua eficácia, trazendo mais divulgação e conhecimento sobre esta nova técnica para que a mesma tenha maior acessibilidade. Dessa forma, o objetivo deste estudo foi analisar a técnica e eficácia da ablação no tratamento de carcinoma renal guiada por método de imagem como a tomografia computadorizada, identificar a função da tomografia computadorizada para o tratamento de massas renais através da crioablação e comparar os métodos ablativos para o tratamento do carcinoma renal.

\section{Material e Métodos}

O presente estudo foi desenvolvido a partir de pesquisa bibliográfica do tipo descritiva exploratória, com abordagem qualitativa sobre a relevância do papel da tomografia computadorizada na crioablação de massas renais.

O estudo foi desenvolvido a partir de revisão bibliográfica de artigos científicos indexados nas bases de dados SCIELO, MEDLINE e outras revistas cientificas, publicados entre os anos de 2010 a 2019. Para a pesquisa foram estabelecidos os seguintes critérios de inclusão: artigos na língua portuguesa e inglesa, publicados em periódicos nacionais e internacionais, voltados apenas para humanos, disponíveis gratuitamente e que abordassem a temática. Foram usados os seguintes descritores: técnicas ablativas, carcinoma renal, tomografia computadorizada, criocirurgia e ablação.

Inicialmente foram encontrados 48 artigos, dos quais foram excluídos aqueles que se 
encontravam em duplicidade e os que não contemplavam o objeto de estudo, restando 29 artigos relacionados ao tema. A partir dos títulos, foram selecionados 10 artigos e, após leitura dos resumos, verificou-se que apenas 6 contemplavam o objetivo do estudo e foram incluídos na presente revisão.

Após a leitura do material selecionado, foram destacadas as principais informações e realizada uma análise descritiva das mesmas, chegando à criação de três categorias: Terapias Ablativas, Radiofrequência ou Radioablação, Crioterapia ou Crioablação.

\section{Resultados e Discussão}

Os periódicos indexados no SCIELO e MEDLINE publicados em outras revistas cientificas, a partir de 2010, publicaram 15 artigos referentes à carcinoma renal, termoablação de massas renais e a tomografia computadorizada como principal método de imagem para guiar o procedimento, acordados com a metodologia do trabalho.

Em consonância com os objetivos adotados neste estudo, foram agrupadas as publicações conforme as categorias previamente definidas: terapias ablativas, radiofrequência ou radioablação, crioterapia ou crioablção.

Tabela 1. Artigos usados nesse estudo.

\begin{tabular}{|c|c|c|c|}
\hline TITULO & ANO & AUTORES & REFERÊNCIA \\
\hline $\begin{array}{l}\text { Cryoablation } v s \text { radiofrequency ablation for } \\
\text { the treatment of renal cell carcinoma: a } \\
\text { meta-analysis of case series studies }\end{array}$ & 2012 & $\begin{array}{l}\text { El Dib } \\
\text { et al. }\end{array}$ & $\begin{array}{l}\text { http://dx.doi.org/10.111 } \\
\text { 1/j.1464- } \\
\text { 410X.2011.10885.x }\end{array}$ \\
\hline $\begin{array}{l}\text { Carcinoma de células renais: classificação } \\
\text { histológica e correlação com métodos de } \\
\text { imagem. }\end{array}$ & 2015 & $\begin{array}{l}\text { Muglia } \quad \& \\
\text { Prando }\end{array}$ & $\begin{array}{l}\text { https://doi.org/10.1590/ } \\
\text { 0100-3984.2013.1927 }\end{array}$ \\
\hline $\begin{array}{l}\text { Utilization and perioperative complications } \\
\text { of laparoscopic cryoablation vs. robotic } \\
\text { partial nephrectomy for localized renal } \\
\text { tumors }\end{array}$ & 2015 & $\begin{array}{l}\text { Weinberg et } \\
\text { al }\end{array}$ & $\begin{array}{l}\text { https://doi.org/10.1590/ } \\
\text { S1677- } \\
\text { 5538.IBJU.2014.0294 }\end{array}$ \\
\hline $\begin{array}{l}\text { Which is the best treatment on a } 2 \mathrm{~cm} \\
\text { complete endophitic tumor on the posterior } \\
\text { side of the left kidney? }\end{array}$ & 2016 & $\begin{array}{l}\text { Garcia, } \\
\text { R. G }\end{array}$ & $\begin{array}{l}\text { https://doi.org/10.1590/ } \\
\text { S1677- } \\
\text { 5538.IBJU.2016.01.03 }\end{array}$ \\
\hline Preditores de mortalidade em pacientes & 2017 & Gurgel, & https://doi.org/10.1590/ \\
\hline
\end{tabular}


submetidos à nefrectomia por carcinoma de

et al

0100-69912017003006

células renais não metastáticos em um centro de referência no Nordeste Brasileiro. EAU Guidelines on Renal Cell Carcinoma:

The 2019 Update.

$\begin{array}{lll}2019 & \begin{array}{l}\text { Ljungberg, } \\ \text { et al }\end{array} & \begin{array}{l}\text { https://doi.org/10.1016/ } \\ \text { j.eururo.2019.02.011 }\end{array}\end{array}$

\subsection{Terapias Ablativas}

O aumento do número de pacientes com câncer renal deve-se em parte aos exames de imagem, tais como ressonância magnética, tomografia computadorizada e ultrassonografia, pois, são capazes de diagnosticar casualmente e ainda em fase assintomática os carcinomas renais (GURGEL et al., 2017). Na Figura 1, podemos observar uma lesão sólida hipervascularizada, de $1,6 \mathrm{~cm}$ no maior eixo, localizada em terço inferior do rim esquerdo, detectada através do exame de Tomografia Computadorizada (TC).

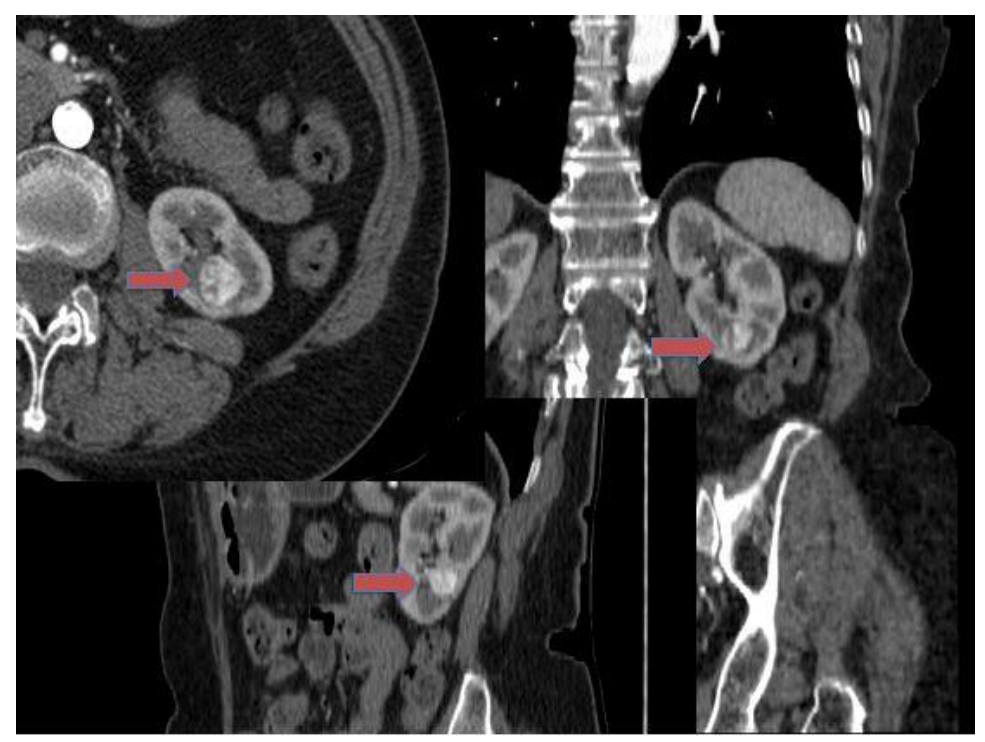

Figura 1. Tomografia computadorizada de abdome, cortes axial, coronal e sagital, todos na fase arterial, com setas apontando para lesão sólida hipervascularizada, de $1,6 \mathrm{~cm}$ no maior eixo, localizada em terço inferior do rim esquerdo. Fonte:( Silva, 2013)

Os exames de imagem tem uma grande importância no diagnóstico das massas renais, pois permitem estabelecer o diagnóstico em estádio precoce, sendo primordiais no estadiamento e planejamento terapêutico da doença. Normalmente, a maioria das massas renais são descobertas incidentalmente em exames de imagem realizados por razões urológicas ou não, com predomínio principalmente do sexo masculino, que representa cerca de dois terços dos casos (MUGLIA \& PRANDO, 2015). Com isso, avanços importantes em relação ao tratamento dos 
tumores renais ocorreram nos últimos anos, tais como a preservação renal associada à segurança oncológica. Segundo SILVA (20135), nos últimos 20 anos o tratamento das pequenas massas renais evoluíram da nefrectomia radical e parcial para procedimentos menos invasivos, como a ablação térmica percutânea ou laparoscópica. Estes avanços resultaram na diminuição da morbidade, na redução do tempo de internamento, na aceleração da recuperação e na preservação da função renal, principalmente em casos de rim único.

O uso da ablação guiada por imagem tem crescido a cada dia como um tratamento alternativo para tumores sólidos de rins, osso, fígado, mamas, pulmões e cérebro. No caso dos rins, este método é utilizado, principalmente, no tratamento do carcinoma de células renais em estágio inicial (SILVA, 2014).

Embora a nefrectomia parcial continue sendo o padrão ouro de referência para o tratamento das massas renais, as diretrizes da American Urological Association defendem a ideia de que as técnicas ablativas térmicas para o tratamento de pacientes com massas renais $<4 \mathrm{~cm}$ são muito válidas para o tratamento, o que torna a crioablação e a radiofrequência terapias promissoras para pacientes com esse tipo de tumor (GARCIA, 2016; El DIB; TOUMA; KAPOOR, 2012).

As técnicas de ablação dos tumores renais têm como principal objetivo destruir o tecido renal doente (tumor), que seria retirado durante nefrectomia parcial convencional ou laparoscópica (ZERATI FILHO et al., 2010; GARCIA, 2016).

Essas terapias são mais indicadas para massas renais localizadas, além de ser a primeira escolha para pacientes com expectativa de vida diminuída ou com comorbidades extensas, já que o procedimento cirúrgico para esses pacientes traz um alto risco de complicações (Robert et al., 2017). Porém, pesquisas mostram que o ideal é monitorar as pequenas massas renais, quando detectadas, a fim de evitar o seu crescimento, realizando procedimento terapêutico precoce, sempre que for indicado, como as terapias ablativas. Aumentar assim o controle da doença e diminuindo a probabilidade desse paciente ser submetido a um procedimento invasivo posteriormente, como por exemplo, a nefrectomia radical.

No tratamento de pacientes com tumores renais localizados é preciso observar três fatores importantes para o sucesso do tratamento: morbidade do paciente, preservação renal e controle 
do câncer (WEINBERG et al., 2015). Porém, como as técnicas ablativas podem ser realizadas através de baixas temperaturas (crioablação) ou altas temperaturas (radiofrequência), o que vai definir a melhor escolha do tipo de ablação a ser usada será a natureza e localização do tumor, pois as duas técnicas ablativas são eficazes no tratamento de carcinomas renais.

No tratamento de carcinoma renal através da crioablação por via percutânea, a TC é muito utilizada, pois, através das imagens adquiridas na tomografia, o médico radiologista intervencionista pode introduzir o probe de forma assertiva no tumor para congelar as células cancerígenas e mata-las, evitando assim que o paciente seja submetido a procedimento cirúrgico aberto (SILVINATO et al., 2015).

Os equipamentos de tomografia disponíveis hoje nas unidades de saúde contam com vários recursos e acessórios que permitem ao médico adquirir imagens seriadas ou, até mesmo, realizar uma fluoroscopia durante a realização do procedimento da ablação, o que permite a obtenção de imagens em tempo real que serão usadas para guiar a introdução do probe no centro do tumor. Esses equipamentos podem também reconstruir as imagens nos diferentes planos anatômicos para obter imagens em 3D que permitem ter uma visão geral do órgão e do tumor que está sendo tratado.

A TC também é usada como método de imagem padrão para avaliar a resposta da doença durante o tratamento sistêmico. Porém, a frequência de acompanhamento por exames de imagem que envolve a exposição à radiação deve ser definida de forma cuidadosa, justificando o benefício clínico provável para evitar potencial risco desnecessário devido à exposição repetida à radiação ionizante (BRASIL, 2014). Portanto, a tomografia é, na maioria das vezes, o exame de primeira escolha pela sua facilidade de acesso, sendo substituída quando o paciente tem restrição ao uso do contraste iodado, que é fundamental para o diagnóstico, ou quando existe alguma outra peculiaridade que pode ser mais bem avaliada na ressonância magnética, por exemplo. No entanto, é preciso ter muita cautela na hora de submeter o paciente a procedimentos tomográficos, para evitara exposição à radiação.

\subsection{Radiofrequencia ou Radioablação}

A ablação por radiofrequência, conhecida também como ablação térmica por 
radiofrequência percutânea - Radiofrequency Ablation (RFA) - é guiada principalmente pela TC, pois, além de direcionar a introdução do eletrodo, ela também permite uma melhor definição do tecido parenquimatoso. A técnica tem se mostrado uma alternativa eficiente e segura para o tratamento de tumores renais sólidos e secundários, podendo alcançar bom controle local, principalmente quando outro tratamento local não é indicado (SILVA, 2014). O ultrassom também pode ser usado como método de imagem para acompanhar a inserção do eletrodo, porém a TC ainda é o método mais utilizado, devido a sua melhor definição de imagem.

A ablação por radiofrequência pode ser realizada através de acesso percutâneo, aberto ou laparoscópico, com o objetivo de levar calor às células neoplásicas e assim causar desnaturação de proteínas celulares, necrose de coagulação e trombose vascular (WEINBERG et al., 2015).

Nesta técnica, é inserido um eletrodo através da pele até atravessar totalmente o tumor. Nesse caso é usada a tomografia como método de imagem para guiar a introdução do eletrodo e garantir o seu posicionamento no local correto. Feito isso, o eletrodo é acoplado a um gerador de radiofrequência, que emite pulsos de radiofrequência produzindo calor a uma temperatura que pode variar entre $60-100^{\circ} \mathrm{C}$, o suficiente para causar uma necrose de coagulação instantaneamente no tumor e, consequentemente, matar as células neoplásicas. Em seguida, é feito o resfriamento com água gelada através do circuito fechado do eletrodo, para evitar a carbonização do tecido adjacente ao tumor e da ponta do eletrodo. O ciclo se repete, em média, três vezes (SILVA, 2014; EL DIB et al., 2012).

De acordo com SILVA (2013), os tumores posteriores devem ser abordados por via percutânea, enquanto que os tumores de localização anterior, mediana ou com envolvimento hilar permitem um melhor acesso por via laparoscópica.

As principais vantagens da ablação por radiofrequência são menor tempo de internação, podendo ser realizada em ambulatório; anestesia local ou de menor profundidade, minimamente invasiva; preservação do tecido adjacente e parênquima renal; tratamento do tumor ainda pequeno e menor risco de hemorragia. Embora possam ocorrer danos, eles são considerados raros quando comparados aos causados por procedimento cirúrgico.

Os primeiros casos de radioablação renal, acompanhados no mínimo por um ano, foram publicados em 2004, quando foi confirmado um resultado de mais de $94 \%$ de controle do 
carcinoma renal para tumores $<4 \mathrm{~cm}($ QUEIROZ, 2011). Assim, além da radioablação ser uma técnica minimamente invasiva, ela permite o início do tratamento ainda em fase precoce, diminuindo os riscos futuros de agravamento da doença ou, até mesmo, de metástase, o que aumenta as chances de cura da doença e o torna um tratamento promissor para os centros de oncologia.

\subsection{Crioterapia ou Crioablção}

A crioablação é o método ablativo mais usado como técnica minimamente invasiva no tratamento dos tumores renais, uma vez que pode ser realizada sem o pinçamento dos vasos renais, descarta a necessidade de dissecção hilar e pode reduzir o risco de isquemia renal (WEINBERG et al., 2015). Assim como a radioablação, ela permite a redução do tempo de internamento e o tratamento precoce, além de preservar o parênquima renal sadio e propiciar uma recuperação mais rápida, permitindo que o paciente retome suas atividades normais em um curto espaço de tempo.

De acordo com GARCIA (2016), a crioterapia ou crioablação é realizada por meio da introdução do crioprobe no tumor, por via percutânea ou durante uma cirurgia laparoscópica, com o objetivo de promover uma temperatura extremamente fria no centro do tumor e assim causar a morte das células neoplásicas. Quando realizada por via laparoscópica, o ultrassom é o meio mais usado como método de imagem para guiar a introdução da crioprobe. Já pela via percutânea, a introdução da crioprobe será guiada por cortes tomográficos, permitindo ao médico visualizar o tumor e guiar precisamente o trajeto da sonda até o seu centro (Figura 2).

As imagens de tomografia são obtidas durante a inserção do cateter e também durante a administração do gás na crioablação ou da radiofrequência na radioablação. 


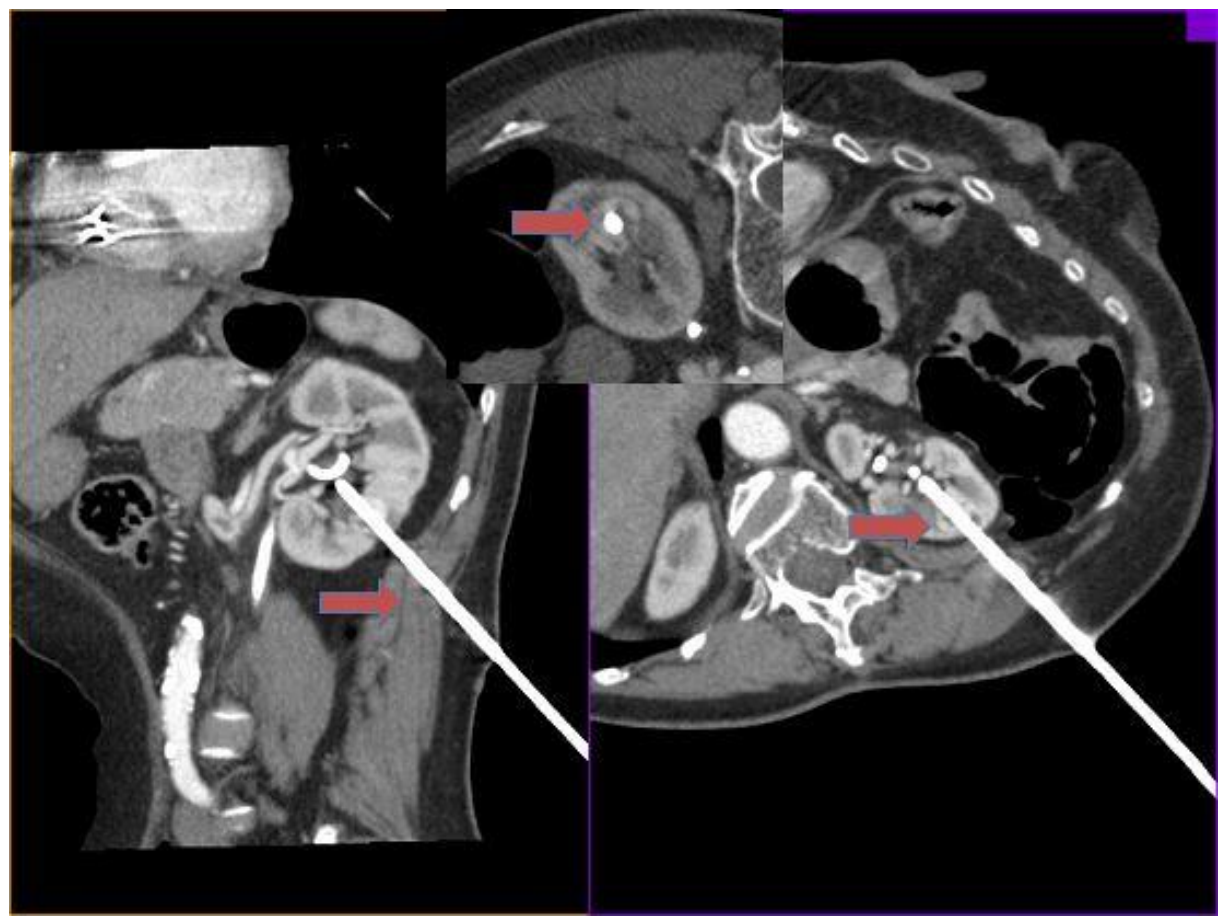

Figura 2. O posicionamento da agulha de crioablação é realizado por fino ajuste tomográfico em diversos cortes. As setas mostram a posição adequada e central da mesma na lesão tumoral. Fonte: SILVA, 2013.

Após o posicionamento das crioprobes na lesão renal, são introduzidos os gases nobres como o argônio ou nitrogênio líquido, criando uma "bola de gelo" na extremidade da sonda, que vai promover o congelamento das células neoplásicas no tumor. Posteriormente, utiliza-se gás hélio para realizar o descongelamento (WEINBERG et al., 2015). O crioprobe é uma espécie de agulha, também chamada de sonda. Ela dispõe de um orifício ou canal por onde são administrados os gases nos centro do tumor promovendo assim o congelamento e descongelamento das células neoplásicas.

Dependendo do tamanho do tumor, pode ser inserido mais de um crioprobe para que todo o tumor seja contemplado pela crioablação. A bola de gelo gerada no tumor através da administração dos gases pode chegar até $-140^{\circ} \mathrm{C}$, causando assim a morte das células neoplásicas e preservando as sadias (Figura 3). Dois ciclos de congelamento e descongelamento são realizados por sessão, a fim de promover a destruição das células neoplásicas. $\mathrm{O}$ procedimento requer o uso de anestesia, que será escolhida de acordo como a via utilizada para o procedimento, ou seja, via percutânea ou laparoscopia (SILVINATO et al., 2015). 


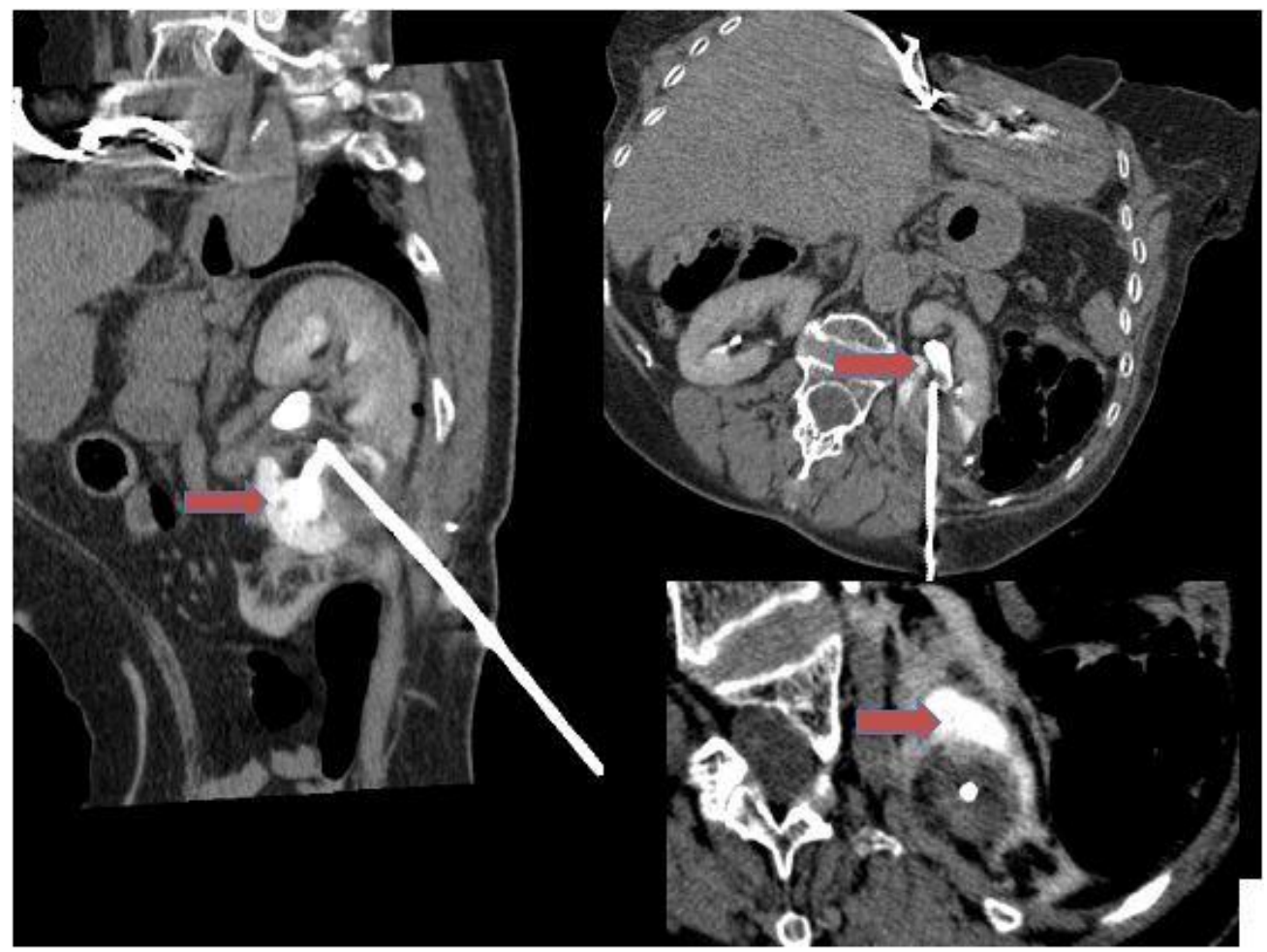

Figura 3.O efeito crioterápico também é confirmado por imagens tomográficas. Setas apontam para formação da "bola de gelo ", a qual promove estase vascular e isquemia celular na lesão. Fonte: (SILVA, 2013)

A morte celular será causada por mecanismos diretos, pois a temperatura pode chegar rapidamente abaixo de $-40^{\circ} \mathrm{C}$, provocando o congelamento e a formação de cristais de gelo na água intracelular que envolve as organelas e a membrana celular, resultando em disfunção enzimática e rompimento da membrana. Além disso, como há congelamento da matriz extracelular, a água deixa o espaço intracelular por osmose, levando a um estado de estresse hiperosmótico, que agrava os danos celulares. E durante o aquecimento, quando a água retorna à célula, ocorre tumefação e lise da mesma. Também ocorre a morte celular por mecanismos indiretos, como a vasoconstrição, compressão dos vasos pela tumefação celular e congelamento do sangue nos pequenos vasos, o que promove a hipóxia celular (SILVA, 2014).

O tamanho da massa renal é uma das características mais importantes para o planejamento terapêutico através da crioablação, pois, apesar da possibilidade de ser inserido mais de um crioprobe, a zona ablativa é muito pequena, o que justifica a sua indicação para tratamento de massas renais $<4 \mathrm{~cm}$. Porém, a crioablação é superior à radiofrequência, porque a bola de gelo é facilmente visualizada na tomografia computadorizada, o que facilita o controle da área a ser ablasionada (GARCIA, 2016). 
Por se tratar de uma técnica minimamente invasiva, a termoablação assim com a radioablação tem ganhado um espaço cada vez maior no cenário de métodos alternativos para o tratamento de carcinomas renais, pois uma vez que é diagnosticado o tumor de tamanho inferior a 4 cm, o oncologista, juntamente com o radiologista intervencionista, tem a opção de dar início ao tratamento de forma conservadora.

\section{Considerações Finais}

A revisão da literatura permitiu evidenciar as técnicas das terapias ablativas como uma alternativa para o tratamento do carcinoma renal. Tanto a crioablação, que usa o frio como principal elemento terapêutico e a radiofrequência, que usa o calor, têm o mesmo objetivo: matar as células cancerígenas, preservando a função e o parênquima renal.

A TC é a principal tecnologia de imagem usada para guiar o procedimento, auxiliando assim no tratamento, pois ela permite ao médico radiologista intervencionista obter imagens em tempo real durante a inserção dos cateteres ou crioprobes, permitindo assim que os mesmos sejam inseridos diretamente no centro do tumor para que seja iniciada a terapia.

Portanto, fica evidente que as terapias ablativas estão em expansão, apesar do método ainda ser pouco divulgado, por ser uma opção de tratamento minimamente invasiva, que pode ser realizada por via percutânea, diminuindo o risco de complicações para o paciente, preservando o parênquima e função renal, permitindo menor tempo de internamento e consequentemente um retorno mais rápido as suas atividades rotineiras, além de tratar os tumores ainda na sua fase inicial $(<4 \mathrm{~cm})$. Essas terapias também podem ser usadas para redução de tumores antes de um tratamento cirúrgico ou até mesmo ser combinada com outros tratamentos oncológicos, a exemplo da quimioterapia e radioterapia. Por isso a tendência é que o tratamento ablativo seja cada vez mais aceito e praticado nos centros de oncologia.

Assim, recomendam-se estudos futuros, de forma a contribuir para a ampliação do conhecimento sobre o tratamento do carcinoma renal através das terapias ablativas como a crioablação e radiofrequência. Outro fator a ser melhorado é a divulgação do método e implantação nos serviços de saúde, pois ainda são poucas as unidades que dispõem deste serviço. 


\section{Referências}

BRASIL. Ministério da Saúde (2014). Secretaria de Atenção à Saúde. Protocolos Clínicos e Diretrizes Terapêuticas em Oncologia. Brasília, DF: Ministério da Saúde, 355p. Disponível em: http://bvsms.saude.gov.br/bvs/publicacoes/protocolos_clinicos_diretrizes_terapeuticas_oncolo gia.pdf

INCA - Instituto Nacional de Câncer José Alencar Gomes da Silva. Ministério da Saúde, Brasil (2020). Coordenação de Prevenção e Vigilância. Estimativa. Incidência de Câncer no Brasil. Rio de Janeiro. Disponível em: https://www.inca.gov.br/sites/ufu.sti.inca.local/files/media/document/estimativa-2020incidencia-de-cancer-no-brasil.pdf

INCA - Instituto Nacional de Câncer José Alencar Gomes da Silva. Ministério da Saúde Brasil (2019). Ministério da Saúde amplia tratamento para câncer renal. Rio de Janeiro, Disponível em: http://conitec.gov.br/ultimas-noticias-3/ministerio-da-saude-amplia-o-tratamento-paracancer-renal

El Dib, R.; Touma, N. J.; Kapoor, A. (2012). Cryoablation vs radiofrequency ablation for the treatment of renal cell carcinoma: a metaanalysis of case series studies BJU International, $\mathrm{v}$. 110, p. 510-516, https://doi.org/10.1111/j.1464-410X.2011.10885.x

Garcia, R. G. (2016). Which is the best treatment on a $2 \mathrm{~cm}$ complete endophitic tumor on the posterior side of the left kidney?. Internation Brazilian journal of the Urology, v. 42, p. 1-7. https://doi.org/10.1590/S1677-5538.IBJU.2016.01.03

Gurgel, M. V. S.; Alves Junior, J.; Vieira, G. B. et al. (2017). Preditores de mortalidade em pacientes submetidos à nefrectomia por carcinoma de células renais não metastático em um centro de referência no Nordeste Brasileiro. Revista do Colégio Brasileiro de Cirurgiões, v. 44, p. 257-262. https://doi.org/10.1590/0100-69912017003006

Ljungberg, B.; Albiges, L.; Abun-Ghanem, Y. al. (2019). European Association of Urology Guidelines on Renal Cell Carcinoma: The 2019 Update. European Urology, v. 75, p. 799-810, https://doi.org/10.1016/j.eururo.2019.02.011

Robert, J.; Motzer, M. D..; Eric Jonassch, M. D. et al. (2017). Guidelines in oncology. Journal of the National Comprehensive Cancer Network, v. 15, p. 804-834. https://doi.org/10.6004/jnccn.2017.0100

Muglia, V. F.; Prando, A (2015). Carcinoma de células renais: classificação histológica e correlação com métodos de imagem. Radiologia Brasileira, v. 48, p. 166-174. https://doi.org/10.1590/0100-3984.2013.1927

Brasil (2014). Diretrizes Diagnósticas e Terapêuticas do Carcinoma de Células Renais. Portaria $\mathrm{N}^{\mathrm{o}} 1.440$ de 16 de dezembro de 2014. Disponível em: http://conitec.gov.br/images/Artigos_Publicacoes/ddt_Carcinoma-CelRenais_2014.pdf. 
Queiroz, M. V. B. Ablação percutânea do Parênquima renal por rádio frequência: estudo experimental sobre a temperatura ideal e o impacto de drogas vasoativas. Tese-doutorado em Ciências, Faculdade de Medicina de São Paulo, USP, são Paulo, Brasil, 67p. 2011. https://doi.org/10.11606/T.5.2011.tde-04082011-155239

Silva, D. N. V. Revisão sistemática sobre terapia ablativa versus tratamento convencional para câncer de pulmão não pequenas células. Monografia - Faculdade Medicina, Universidade Federal da Bahia - UFBA. Bahia, Brasil. 33p. 2014. Disponível em: http://repositorio.ufba.br/ri/handle/ri/17867. Acessado em 15 de Agosto de 2018.

Silva, F. C (2013). Recomendações Clínicas no Tratamento do Carcinoma de Células Renais. $1^{\mathrm{a}}$ ed. Lisboa, EORTC, 226p.

Silvinato, A.; Nogueira, L. M.; Machado, M. T. et al.. (2015). Ablação Térmica nos tumores Renais. Portal da Urologia, Disponível em: https://portaldaurologia.org.br/medicos/wpcontent/uploads/2015/09/ablacao_termica_nos_tumores_renais.pdf. Acessado em 15 de Agosto de 2018.

Weinberg, A. C.; Woldu, S. L.; Wen, T. et al. (2015). Utilization and perioperative complications of laparoscopic cryoablation vs. robotic partial nephrectomy for localized renal tumors. Internation Brazilian Journal Urology, v. 41, p. 473-485. https://do i.org/10.1590/S1677$\underline{\text { 5538.IBJU.2014.0294 }}$

Zerati Filho, M.; Nardozza Júnior, A.; Reis, R. B. (2010). Urologia Fundamental: Câncer de Rim. $1^{a}$ ed. São Paulo-SP. Planmark Ltda, 420p. 